\title{
LETTER
}

\section{Noninvasive mechanical ventilation for very old patients with limitations of care: is the ICU the most appropriate setting?}

\author{
Raffaele Scala*1 and Antonio Esquinas ${ }^{2}$
}

We read with interest the recent article by Schortgen and colleagues [1], who emphasized the role of noninvasive ventilation (NIV) as a 'ceiling' ventilatory treatment within the 'do-not-intubate (DNI) context', which turns out to be the largest indication in octogenarians given their high risk of developing life-threatening complications during invasive ventilation. As underlined by the authors, NIV may be considered a valid option in a wide range of 'DNI-linked' clinical scenarios, ranging from life support to a purely palliative tool [2].

Bearing this scenario in mind, we wonder whether the intensive care unit (ICU) is the best setting for NIV in 'older elderly DNI patients' [2,3]. While the use of NIV in patients with acute respiratory failure without preset limitations on life-sustaining treatment may be implemented in different settings (ICUs, respiratory ICUs (RICUs), and emergency rooms), depending on the typology of acute syndrome and the likelihood of success, the ideal care for 'DNI patients' is likely to be more appropriate outside the ICU [2]. In fact, for these patients for whom endotracheal intubation is questionable or care is centered largely on symptom palliation or both, NIV failure requires the intensification of comfort measures only, adequately performed in totally or partially 'open' environments [2,3]. The option of NIV in end-of-life decisions is emerging in European RICUs, where a large majority of DNI patients are treated by pulmonologists [3]. This is not surprising, as RICUs differ substantially from ICUs in terms of patient population, staffing, monitoring, and use of NIV as the preferred ventilatory approach [4]. Furthermore, a recent American survey showed that the stated use of NIV and the confidence in its utility in end-of-life patients were greater for pulmonologists than for intensivists [5]. A pulmonologist's point of view may be influenced by caring for end-stage respiratory patients over the entire spectrum of their

*Correspondence: raffaele_scala@hotmail.com

'Respiratory Ward and Respiratory Intensive Care Unit, S. Donato Hospital, ASL 8 Arezzo, Via Nenni 20, 52100 Arezzo, Italy

Full list of author information is available at the end of the article illness as opposed to the greater focus on acute care among intensivists.

In conclusion, the assignment of 'older elderly DNI patients' to an environment, such as the ICU, that was originally designed to treat patients without preset limitations of care (that is, invasive mechanical ventilation) raises financial and ethical concerns, namely (a) the questionable cost-utility ratio of allocating the precious limited ICU resources for patients whose needs may be met by lower levels of care (that is, nurse workload) and (b) the inappropriateness of a 'close environment' for managing respiratory patients who would like to spend the end of their lives near their friends and family. Hospital administrators should identify, in expert pulmonology units, the optimal setting for implementing NIV within the 'DNI and end-of-life context' to achieve economic and ethical benefits that surpass those of the ICU.

\section{Abbreviations}

DNI, do-not-intubate; ICU, intensive care unit; NIV, noninvasive ventilation; RICU, respiratory intensive care unit.

\section{Competing interests}

The authors declare that they have no competing interests.

\section{Author details}

'Respiratory Ward and Respiratory Intensive Care Unit, S. Donato Hospital, ASL 8 Arezzo, Via Nenni 20, 52100 Arezzo, Italy. ${ }^{2}$ Intensive Care Unit, Hospital Morales Meseguer, Avenida Marqués de Los Velez s/n, 30500, Murcia, Spain.

Published: 7 June 2012

\section{References}

1. Schortgen F, Follin A, Piccari L, Roche-Campo F, Carteaux G, TaillandierHeriche E, Krypciak S, Thille AW, Paillaud E, Brochard L: Results of noninvasive ventilation in very old patients. Ann Intensive Care 2012, 2:5.

2. Scala R, Nava S: NIV and palliative care. Eur Respir Mon 2008, 41:287-306.

3. Nava S, Sturani C, Hartl S, Magni G, Ciontu M, Corrado A, Simonds A; European Respiratory Society Task Force on Ethics and decision-making in end stage lung disease: End-of-life decision-making in respiratory intermediate care units: a European survey. Eur Respir J 2007, 30:156-164.

4. Scala R, Corrado A, Confalonieri, Marchese S, Ambrosino N: Increased number and expertise of Italian Respiratory High-Dependency Care Units: the second national survey. Respir Care 2011, 56:1100-1107.

5. Sinuff T, Cook DJ, Keenan SP, Burns KE, Adhikari NK, Rocker GM, Mehta S, Kacmarek R, Eva K, Hill NS: Noninvasive ventilation for acute respiratory failure near the end of life. Crit Care Med 2008, 36:789-794.

\section{doi:10.1186/cc11352}

Cite this article as: Scala R, Esquinas A: Noninvasive mechanical ventilation for very old patients with limitations of care: is the ICU the most appropriate setting? Critical Care 2012, 16:429. 